\title{
Renewable Energies, Option of Future
}

\author{
Ramón M ${ }^{\mathrm{a}}$ Mujal-Rosas ${ }^{1}$. Jasmina Casals-Terré $\oslash$. Joaquim Lloberas-Valls ${ }^{1}$. \\ Universidad Politécnica de Cataluña. \\ ${ }^{1}$ Departamento de Ingeniería Eléctrica. ${ }^{\diamond}$ Departamento de Ingeniería mecánica. \\ Campus de Terrassa. C/ Colon $\mathrm{n}^{\mathrm{o}}$ 11, Terrassa (Barcelona). CP: 08222. \\ Tef: 9373980 35. Fax: 9373982 36. E-mail: mujal@ee.upc.es
}

\begin{abstract}
The solar photovoltaic power, solar thermal power, wind power, biomass, biofuels, energy from waste power \& small hydro power stations, etc. are part of the installations that allow the use of a huge number of different energies, called renewable energies, clean energies or new energies.

In fact the innovation resides fundamentally in technologies applied today to obtain energy, and the role assigned to these methods of power generation in the world of energy generation. This paper presents the development of this type of energies emphasizing its use to generate electricity.

The advantages and trade-offs will be analyzed, as well as short and mid term expectations, studying their incidence on the environment. Moreover, the main renewable energies will be described: Minihydroelectric power stations, solar thermal stations, solar photovoltaic stations, wind power stations biomass and urban waste power stations.
\end{abstract}

\section{Key words}

Renewable energies wind energy, solar, biomass, hydroelectric minipower stations....

\section{Introduction}

Traditional energies (thermal and nuclear) present great disadvantages mainly during their generation and use. Main problems are due to polluting effects, as well as the implicit danger when they are used. Besides, the fuels used are limited and frequently with high prices.

All these disadvantages motivated that some countries started to feel an increased sensitivity towards the environment, forcing the study of new alternatives for electrical energy generation. These new technologies have to be clean and the energy obtained without altering earth ecosystems.

Nowadays, the main problem that limits the use of the renewable energies in front the traditional ones, is technology. The technology used is not sufficiently developed to obtain great amounts of energy with high efficiency.

However, in the last years there has been a very reasonable increase in the electricity generation using revewable energies that have unquestionable advantages versus the classic electricity generation means:

- They do not pollute the environment

- They are not dangerous
- The resources usually have low price

- They use unlimited resources (sun, wind, waste, biomass, etc).

- They are more easily adjustable.

But, these type of generation is not perfect, these energies alter the ecosystems where they are installed.

\section{Development of the renewable energies.}

The development of facilities, that use renewable energies as a source, received a great impulse due to the policy of power diversification that almost all developed countries began during 1973 and 1979 to face the increased price of petroleum. After that, the preocupation to contain rationally the consumption of the main power resources whose well-known reserves are limited and the reduction of the power dependency to other countries, has become priorities of power policy specially in countries with limited resources of this type.

Recently, new power resources due to its reneweable character and its smaller environmental impact have been potentiated because there is an increasing preocupation to limit and reduce as far as possible the effects on environment of the power generation activities as well as an interest to increase the efficient use of energy (goal intimately related).

Spain is one of European countries with a greater level of development in the use of renewable energies. In fact, from the fifteen countries of UE, and with data from 2002, Spain is third in the use of wind energy, hydroelectric minicentral and thermal solar energy; It is forth in energies like photovoltaic, urban biomass, or waste energy.

Since 1980, administrations, main electrical companies and private sector, have dedicated important technic, economic and human efforts to investigation, implantation and later maintenance of facilities of this type. Moreover, there are several national manufacturers of materials and components for wind and solar (photovoltaic and thermal) facilities. Spanish manufacturers have a very promising future, their initiatives will allow to do high level investigation in renewable energies. These energies will play a very important role in the industrialized countries in the future. 


\section{Electrical minipower stations.}

The hydroelectric minipower stations are a future approach, since the Spanish hydroelectric development should be based on quality more than on quantity. This will allow to face the abrupt variations of the demand of energy and at the same time to provide energy in the rush hours, or to take advantage of locations where the great hydroelectric power stations could be in conflict with other forms to use the ground.

In 1981 the Administration and electrical companies started up a Plan for the recovery of a hundred of these facilities. Also, during the eighties several legal initiatives took place (Law on the Conservation of the Energy, as well as the Law for Utilitzation of the Hydroelectric Production in Small Power stations). These laws promoted the construction, extension, automatization or adaptation of facilities with a power of until 5MW. The interest by the minipower stations is reflected in the Plan of Renewable Energies, that anticipates an increase of the power and production of these.

The possibilities of minihydraulic power station development are considerable, due to the abundant potentially explotable resources, hydroelectric potential in Spain is considered to be $6700 \mathrm{GWh} /$ year. The renewed interest of inversion in this area is also important

The minihidraulic power stations environmental impact is, in general, similar to the one generated by bigger hydroelectric power stations, but in a smaller scale, since these facilities do not have a great capacity of regulation, they take reduced zones and cogoverning measures are simple to apply and very effective. In fact, minihidraulic power stations that usually operate in mountainous zones, have two dangerous effects: the sections of river affected and steepy overbanks of valleys by where the pipes run.

The affected areas of the river go from the pick up point to the jump. These areas register reductions of volume that sometimes can suppose its total drying. Logically, alive organisms that live in the regulated areas are affected due to volume oscillations. Downstream, there are also picks of volume when the installation is working in unesteady regime, although they are usually absorved quickly.

The mainchanel and overbanks of the river are mainly affected during pipes construction process. The injurious effects of these conductions are more significant when they are in steepy overbanks due to the impact of erosion. Finally, pipes influence in the visual impact, too.

\section{Thermal solar energy}

The principal system used to obtain energy from the sun is the thermal. In this technic the way to obtain energy is through collectors. A collector is a surface exposed to the solar radiation, that absorbs its heat and the heat is transmited to a fluid. There are different techniques used for this porpouse, based on the temperature that can reach the heat carrier fluid:

- Low-temperature systems: (unglazed flat plate collectors). The fluid temperature remains below the boiling point (between $50^{\circ} \mathrm{C}$ and $90^{\circ} \mathrm{C}$ ). These temperatures can not generate steam, making impossible the use of turbines for electrical energy generation. Low-temperature collectors have been widely used for swimming pool heating and residential hot water generation.

- Medium temperature collectors. The temperature range goes from 100 up to 300 degrees Celsius. At this range it is possible to generate steam and therefore electrical energy. Due to the fact that temperatures are not excessively high, its main application is steam production for small nindustrial processes or heating of great water surfaces.

- High temperature focusing collectors The temperature of the fluid range from $300^{\circ} \mathrm{C}$, up to $3000^{\circ} \mathrm{C}$ in some cases. Now it is possible to generate electric energy

In medium temperature facilities more panels are used than in low temperature facilites. Moreover, the shape of the collectors has been carefully studied: parabolic, hyperbolic. In fact it has been proved that cylindricalparabolic collectors allow the maximum efficiency absorption of solar radiation

In high-temperature collectors, (from $300^{\circ} \mathrm{C}$, up to $3000^{\circ} \mathrm{C}$ ), special types of collectors are used. These collectors are focusing collectors, whose philosophy consists in increasing the radiation by surface unit. There are several forms and systems of doing this, but the most common way is enhanced the collector temperature capabilities by being mounted in a sun-tracking system. These collectors have the following parts:

- Reflecting surface.

- Absorbent surface.

- Transparent cover.

According to the sun tracking system used we have:

- Systems with longitudinal motion (Single-axis) from east to west

- Systems with latitudinal motion (Single-axis) form north to south.

- Systems with complete motion (Dual-axis), track the sun on all axes. Systems with dual-axis tracking concentrate solar energy the most and therefore produce the highest temperatures, but are the most complex and expensive

Shape of the reflecting surface is the most important part of the collector. They can be:

- Non-Truncated compound parabolic concentrators (CPC). These have symmetrical branches of 
parabola, covering equal angles to both sides of the reflecting surface.

- Truncated compound parabolic concentrators: These have nonsymmetrical branches of the parabola, having one or both branches truncated.

- Asimetric they do not have symmetry respect to the axis of the concentrator.

- Fresnel lenses: they are a derivation of the planoconvex lenses.

One of the most representative facilities that uses thermal solar energy are the thermoelectrial power stations of central receiver. These consist of a big surface of heliostats, in other words great mirrors that reflect the solar radiation and concentrate it in a small central receiving point. Normally this central point is installed in a tower, for this reason they are called solar power station of tower or receiving power station.

The receiver transmits the heat solar radiation to a heat carrier fluid (water, salts, sodium, air, etc.) which is in the primary circuit. This fluid goes to the heat exchanger, vaporizing a second fluid (usually water) that circulates in the secondary circuit. Steam generated is used in a turbine-generator system to produce electricity.

These centrals usually have some kind of heat storage systems, to avoid fluctuations in the solar insulation. These systems are fundent salts, thermal oils, stones or any other material with a high thermal inertia. These materials are used to store the heat as much as possible.

Finally heliostats have some electronic mechanism capable to receive periodic information to track sun position. Being all the time in the optimal position to receive the maximum insulation and being able to concentrate it efficiently to the central receiver.

In summary, low-temperature and medium-temperature thermal solar systems are used usually in domestic heating, water domestic heating, drying materials, swimming pool heating and small industrial steam production.... On the other hand, high-temperature systems are used to produce electricity, but they are in an experimental stage due to the high prices of its components and its low efficiency.

From the environmental point of view, the generation of electric power through thermal solar energy, is not harmful: there is no atmosferic emission, no liquid or solid waste and there is no use of fuels. But, big solar thermal stations can have an important impact of the scenry of the area affected, causing conflicts with others ground uses. Moreover, broken glasses from heliostats, oils and other waste should be considered when analysis the environtmental effects of this installations.

\section{Photovoltaic solar energy.}

In 1839, Edmond Becquerel noticed that, in addition to heat, the sunlight that is absorbed by certain materials can produce small quantities of electricity. This curious phenomenon was limited to measuring light levels in photography until the 1950s. Then, the combination of improved purification techniques for semiconductors, the advances in solid state devices beginning with the development of the transistor in 1947, and the needs of the emerging space program, led to the development of photovoltaic cells.

Photovoltaic cells convert sunlight directly into electricity by the interaction of photons and electrons within the semiconductor material. To create a photovoltaic cell, a material such as silicon is doped with atoms from an element with one more or less electrons than occurs in its matching substrate (e.g., silicon). A thin layer of each material is joined to form a junction. Photons, striking the cell, cause this mismatched electron to be dislodged, creating a current as it moves across the junction. Through a grid of physical connections, the current is gathered. Various currents and voltages can be supplied through series and parallel arrays of cells.

Solar cells generate current all over their surface. Electrical connections for the photovoltaic cell are necessary in order to utilize the energy in an electric circuit. Solar cells have a metallic collector grid to collect the current generated. There is a trade-off between electrical resistance losses and the loss of active surface area on the solar cell from shading by the collector grid. The highest quality grids are produced using photolithography for image transfer. Crystalline cells typically use a layer of aluminum or molybdenum. The typical thin film does not use a metal grid for the electrical contact, but a transparent conducting oxide, such as tin oxide, indium oxide, or zinc oxide.

Although there are different of photovoltaic panels, some of the basic characteristics can be summarized as:

- Photovoltaic cells convert sunlight directly into electricity (they use direct radiation, but not diffuse).

- Generated electricity is DC.

- From each photovoltaic cell are obtained $0.58 \mathrm{~V}$ when irradiation is $1 \mathrm{~kW} / \mathrm{m} 2$.

- The cells are connected in groups of 36 units forming a solar panel.

- They can be used to provide energy to isolated installations.

- It is a clean energy environmentally speaking.

Photovoltaic cells are connected to each other on a module called solar panel, a set of solar panels correctly arranged form a solar power station. The electrical characteristics of these facilities are determined by the number and type of connection of the cells

There are several different type of connections:

- Serial: P part of one cell is connected to the $\mathrm{N}$ part of the next one, and so on. The voltages of each cell are added, the current is equal for all the cells.

- Parallel connection: All the P-parts of the cells are together on one side and all the N-Parts of the cells 
are connected on another terminal. The voltage is the onecorresponding to a cell, and the current is the sum of the currents through all cels.

- Mixed connection: It is a combination of parallel and serial connections.

From the environmental point of view, this type of energy is similar to the thermal energy. It does not causes many problems. In small facilities, the only problem can be originated by the visual impact, always very subjective. However in average and big solar power stations, the main problem comes from the huge area taken $\left(6 \mathrm{~m}^{2}\right.$ by $1 \mathrm{~kW}$ generated). There are differences between the facilities connected to the network and isolated ones according to the area used. But socioeconomical consequences are positive, since they allow to carry out eletrical connection to isolated places where normal procedures of electrification are not economically suitable.

Finally the waste coming from the panels when they are broken or out of order should be carefully treated and taken into consideration when planing this type of installation

\section{Wind energy}

The source of energy of an aeolian power plant is the wind, or rather, the mechanical energy that in form of kinetic energy transports the air in motion. The wind is originated by the unequal heating of the surface of our planet, which originates convective movements of the atmospheric masses.

Earth receives a great amount of energy coming from the Sun. This energy, in favorable places, can be of the order of $2,000 \mathrm{kWh} / \mathrm{m}^{2}$ annually. Only $2 \%$, of this energy is transformed into aeolian energy being able to generate a power of $10 \cdot 10^{11} \mathrm{GWh}$ per year.

The wind energy was already used by ancients, mainly in marine transportation and agricultural facilities. The novel thing of this energy is its use for electrical energy generation, apprearing at the beginning of the 20th century in Denmark. The great advance comes from the technology, new materials, the search of appropriate places to locate the parks (aeolian station), etc., In fact, efforts go directly to develop solutions that allow a better efficiency of this type of facilities.

In order to be economically viable, its primary source, the wind, must fulfill some minimum requirements that make the generation efficient. These requirements are:

- The range of wind speeds suitable to obtain a power density in the following values:

- $1000 \mathrm{~W} / \mathrm{m}^{2}$ : the efficiency is good.

- $200 \mathrm{~W} / \mathrm{m}^{2}$ : the efficiency is normal.

- $50 \mathrm{~W} / \mathrm{m}^{2}$ : the efficiency is low.

- Below $50 \mathrm{~W} / \mathrm{m}^{2}$, these power stations does not have interest.

- The wind direction should be as stable as possible.
- It should be continuously blowing.

Regarding to wind turbines, there are several types:

- Vertical axis wind turbine

- Diferential drag wind turbine.

- Screen wind turbine.

- Moving valves wind turbines.

- Rotating blades wind turbine

- Horizontal axis wind turbine.

- Classical windmills.

- Slow or fast wind turbines.

Great variety of machines have been proposed to harness wind energy. Modern wind turbines come in two basic configurations: horizontal axis turbines and vertical axis turbines. The majority of modern wind turbines are electricity-generating devices. They range from small turbines that produce a few tens or hundreds of watts of power to relatively large turbines that produce $1 \mathrm{MW}$ or more.

For the horizontal-axis wind turbine (HAWT) the axis of the rotor is parallel to the wind direction, the angle of attack at any point along the blade is more-or-less constant for a given wind speed. Up to the stall point, the lift force created is proportional to the angle of attack. On some HAWTs the rotor is placed downwind of the tower to improve the yaw behaviour of the rotor -its ability to track the wind as its direction changes- and improve the clearance between tower and blades under load. An upwind rotor does not have the disadvantage of operating through the disturbed airflow behind the tower, with the associated aerodynamic noise penalty that this configuration brings. But upwind rotor wind turbines need an orientation devices. This kind of configuration is the most commonly used nowadays.

In the vertical-axis configuration (VAWT) (also known as the Darrius or eggbeater-shape), the rotor axis is perpendicular to the wind stream. Its blades spin about an axis perpendicular to the ground, capturing energy from winds blowing from all directions. The angle of attack at any point on the blade varies in time, so the aerodynamic power and loads are unsteady. Although this is a complication, a vertical-axis wind turbine has the advantage of not requiring re-alignment with the wind when its direction changes. In this configuration the drive train and generator are located under the rotor near the ground for easy maintenance and inspection. The shape also allows the larger rotor to be placed upon existing turbine bases, if desired. This design of the rotor makes it easier to bend the turbine blades into the desired shape and makes better (and more profitable) use of available sites in a wind power plant. But the efficiency is lower than in horizontal-axis configuration.

The number of blades on a rotor is dependent on size, with two blades being generally preferred on larger machines, and three blades for machines under $500 \mathrm{~kW}$. For a two-bladed rotor there would be a cost reduction associated with the reduced rotor weight, and a reduced gearbox cost because of higher running speed; but the 
three-bladed rotor produces slightly more power. The increased tip speed of a two-blade rotor might also cause increased aerodynamic noise.

In the design of horizontal-axis wind turbine, the rotor is one of the most important components which has two, three or up to six blades. The rotor is the most expensive part of the wind machine, around a $30 \%$ of the total investment.

Altohugh traditionally the blades were made of steel recently a new wide variety of materials have been used for blade manufacture, including glass fibre on a foam core, glass-reinforced polyester (GRP), wood/epoxy laminat. Component fatigue is obviously a major concern to a manufacturer, and very roughly speaking the stochastic loading associated with turbulence accounts for $50 \%$ of the fatigue damage on the rotor. Continual wind veering means that for a large proportion of the time the rotor is misalign to the wind, resulting in loss of power, increased blade bending moments, and torque at the yaw axis. It has been found counter-productive to make the yaw controller too active in following the wind direction changes, since that in itself can significantly increase fatigue damage. Any kind of imbalance in the rotor can also add to the vibratory loading on the yaw drive.

The second part is the wind turbine itself. Inside the is the mechanical part (gearbox, aerodynamics breaks, mechanical breaks...) and the electrical part (generator), which allows the transformation of energy from kinetics to electricity.

The tower is the most conventional element. It can have a shape similar to electrical towers or there are also cylindrical or more complex shapes. Usually they are built out of metal or concrete. An important point to consider when designing the tower, is that the modes of vibration should be suitable to be connected to modes of vibration of the blades.

The operation of this type of machines is simple. The turbine blades collect the energy from the wind, and convert it into the rotational energy of a shaft. This power is then transferred to a gearbox, where the rotational speed is increased, and the torque decreased. The rotational energy is then converted into electrical power by a generator. A break is also included in the drive train for use during servicing, or in emergency situations.

A wind turbine generally consists of several standard components:

- Direction control devices: They keep the rotor in front of the wind, diminishing the changes of direction of the rotor with the changes of wind direction; these changes of direction cause losses and reduce efficiency.

- Speed control devices: The variability of the wind raises the need for power control. Power cannot be allowed to increase much beyond the rated power of the machine because of the risk of damage to the gearbox and generator.

- Transmission devices: Gear box used to increase the speed of the rotor connected also to the electrical generator. It is a multiplier placed between the rotor and the generator.

- Generator: for DC generation (DC) dynamo, and for $\mathrm{AC}$ generation (AC) generators, these can be synchronous or asynchronous.

From environmental point of view, we have to consider the following:

The influence of wind generated energy: on conventional electrical energy generation is due to the fact that aeolian generators produces a great number of overtones that affect the net. This problem can be solved, for example, using frequency converters with direct control torque, that eliminate overtones and allow to practically obtain active intensities $(\cos \varphi=1)$.

The appearance of turbines on the landscape is one of the few negative aspects of wind turbines. The larger output units are very big, up to $50 \mathrm{~m}$ high with three $15 \mathrm{~m}$ blades. To have large numbers of wind turbines scattered on every hill or ridge in a region would undoubtedly be an eyesore. But the reaction that produces is diverse: whereas for somebody may represent an aggression, for others, even gives a note of modernity to the landscape.

More important than the previous one is the impact on birds. The great mills located in rows at the top of hills originate lots of collisions between birds and the blades. For this problem truely effective solutions do not exist. We mainly should avoid to install aeolian parks in zones with protected species or in their migratory routes.

The impact on the flora has an easier solution. When a wind farm is made the scenry is altered due to construction work. This altered landscape must be recovered trying to reproduce as far as possible its natural surroundings. This restoration should be done with similar vegetal and animal species.

One of the worst environmental impacts of wind energy, is due to the noise produced by wind machines during their operation. This noise, however, can be classified in two groups according to the origin of the sources:

- Mechanical noise coming from the generator (Gearbox, coils, connections, etc.). This noise is being diminished continuously, thanks to technological improvements such new designs and use of new materials.

- Aerodynamic sound coming from the motion of the blades. This noise can have two origins: the noise produced when an unstable flow of the air impacts on the blades (usually called broadband), this has a certain rate. Low Frequency noise is inaudible for people, but it can produce annoying vibrations in buildings located to a certain distance. This LF noise depends on the number and shape of the blades, and it depends also on local turbulence, because when the wind speed and the turning of blades is higher its 
effects are more important. For this reason, actual wind machines designs try to obtain similar power with lower turning speeds.

Although permissible limits of noise vary according to each country legislations, it seems reasonable to accept as a limit of noise: industrial noise, between $40 \mathrm{~dB}$ and $60 \mathrm{~dB}$.

\section{Biomass energy.}

Biomass refers to organic matter which can be converted to energy. Some of the most common biomass fuels are wood, agricultural residues, and crops grown specifically for energy. In addition, it is possible to convert municipal waste, manure or agricultural products into valuable fuels for transportation, industry, and even residential use. There are an uncountable number of woodstoves being used to produce heat for buildings or for cooking in the world, making biomass one of the most common forms of energy. Utilities and commercial and industrial facilities are also using biomass to produce electricity.

This new source of energy has a promising future, representing right now $45 \%$ of the renewable energy generated in Europe and almost $50 \%$ of generated energy in Spain

In Spain the potential biomass power goes up to 24 Mtep; 19,6 Mtep and it comes from energetic crops power and 3,8 Mtep from forestal and agricultural residues. Biocombustibles production and an excessive use of forest and agricultural residues is not desirable, due to its repercussions on biological diversity and hydrologic cycle, because we don't have to forget that it is most import producing food than biocombustibles

Biomass is envioronmentally respectful, because it contributes to palliate, at least partly, the greenhouse effect and promotes reforestation. Its explotation has associated problems due to combustion processes, although emission of sulfur and nitrogen oxides are lower than in conventional processes. It is important to remember that uncontrolled crops in extensive zones with fast growthing nonnative species, like eucalyptuses, to supply raw material to biomass facilities, has a very negative impact on the ecosystems, transforming them and moving original species from the zone.

A solution to these problems happens to obtain biogas from cattle waste digestors, this will reduce methane emissions. This biogas, will have to be promoted in the future to reduce pollution, obtain fertilizers and generate electrical energy.

\section{Urban waste energy.}

Urban solid waste is a reality that day after day appears to be used in more population concentrations. The causes of this problem are: the fast growth of population; the population concentration in urban areas; the one-use products, and the use of packages made with nonreusable materials.

Although the best way to manage waste is not generating it, as well as reducing its volume and toxicity, once the problem exists, this can only be lessen using waste to produce energy. Now in Spain, urban waste have four different types of treatments: Landfilling, incineration, composting, and recycling. From power point of view the only possibility is incineration.

Final destiny of the solid urban waste in Spain is: Landfilling 76\%, composting 19\%, incineration 4,5\%, recycling $0.5 \%$. Regarding to the type of waste, the main fraction is organic matter (more than 160 million annual tons on a total of $280 \mathrm{Mtn}$ ), having urban origin (domestic, markets, hotels), industrial, agricultural or forestal.

A future trend due to serious environmental problems caused by incinerators has produced an important development of pyrolysis, organic waste is heated in the absence of air to produce a mixture of gaseous and liquid fuels and a solid inert residue (mainly carbon). Pyrolysis generally requires a consistent waste stream such as tyres or plastics to produce a usable fuel product. But this process is expensive and requires high technology. These are some of the reasons why existing plants are still experimental.

Due to environmental problems caused by incineration, it has to be considered as an avoidable alternative. All possible methods of solid waste management if they are used incorrectly or incompletely, they can produce a huge negative impact on the surroundings. Uncontrolled landfilling can produce hidrologic pollution and incineration, atmospheric pollution.

Atmospheric pollution is evaluated through the analysis of polluting components. The presence of organicchlorinated micropolluting agents, $\mathrm{CO}$ and heavy metals in the smoke, are eliminated changing design solutions. These solutions keep gases, more than two second with an oxygen concentration superior to $6 \%$, to a temperature between $850^{\circ} \mathrm{C}$ and $1000^{\circ} \mathrm{C}$. The inferior limit assures that the organic-chlorinated compounds disappear and the superior limit prevents heavy metals from remaining in the smoke.

Other factors like noises, dirt, etc. in a plant of this type, practically do not take place.

\section{Conclusions}

First part of governmental legislation that establishes a considerable support to the renewable energies was introduced in 1994. Through a Law that commited all electrical companies to pay a premium by the green energy in a period of five years. In general this system to help the protection of the environment was already working in Germany where they already had a similar Law. 
In 1998, the government reaffirmed its commitment with renewable energies with a new law (Real Decree 2818/1998) designed to harmonize this system with the continuous opening of the European power. Like in other countries, all the companies involved in the electrical production are privated and its activity, as far as generation and distribution of energy, is clearly separated.

In 1998 Law a minimum objective was established to have at least a $12 \%$ of the energy of the country coming from renewable sources in 2010, in agreement to European Union objective, and a new norm was introduced to pay the green energy produced. This represent for aeolian energy producers, that by each unit of electricity produced, a price equivalent to $88,5 \%$ of the sale price to the consumers. The explotation of hydraulic minipower stations, has very favorable short term perspective because they have a reduced environmental impact. It can be said that during the nineties more than 500 new or rehabilitated minipower stations have been installed giving an additional power of $1000 \mathrm{MW}$. In the Spanish country the minipower stations represent a $53 \%$ of the installed power.

Solar energy, is the method that has more possibilities to offer. It may be a genereal trend in next houses generation to be designed to absorb the maximum solar energy that receives, this could represent 100000 tep, with a collector surface of $300000 \mathrm{~m}^{2}$.

Due to its high prices active collectors need to be meticulously studied to make them more competitive.

The photovoltaic power plants will benefit of the new technological development that in a very short term will allow an important reduction of manufacturing costs of solar panels and, therefore, the cost of the whole facility. But right now, from all renewable energies, solar energy does not reach the $0,3 \%$ in Spain.

Regarding to wind energy, the wind farms installed recently uses low or medium power machines with designs in the rank of $50-200 \mathrm{~kW}$. The future goes towards the construction of installation with greater power, (between 200 and $400 \mathrm{~kW}$ ) and, also, to use zones of our territory with a high potential. In the Spanish power generation environment, the aeolian energy represents $36 \%$ of the total of the renewable energies.

The use of urban solid waste to incinerate and recover the energy is a way of waste management that has great possibilities of being increased in the future, due to the tendency to centralize the collection and treatment of urban waste. Nowadays is difficult to have areas to fulfill with waste, then incineration is another solution. In Spain, more than 30 projects of incinerators are being carried in high density population areas,. These installations could suppose near 250MW of installed electrical power.

On the other hand, our country has important forest resources, although it is truth that this resources has important drawbacks. The total solid urban waste, representw a $4 \%$ of the total renewable energies, and biomass goes up to $7 \%$.

\section{Referencias.}

[1] Diversas “Monografias técnicas de energías renovables”. Editorial Progrensa 1998.

[2] Diversos "Estudios monográficos sobre las energías renovables" Instituto Catalán de la Energía. Generalitat de Catalunya. Años 99-00.

[3] "La electricidad en España" Centro de publica ciones UNESA. 1996.

[4] "El sector eléctrico y el medio ambiente" Centro de publicaciones UNESA. 1996.

[5] Energías renovables: alternativa ante la dependencia de los combustibles convencionales ". Artículo revista energética. 2000.

[6] "Las centrales eléctricas y las energías renovables". Centro de publicaciones de UNESA-98 
Table I: Maximum power installed in each autonomic community to generate electricity using renewable energies (Data by Autonomic Communities and types of used energy. Year 2001).

\begin{tabular}{|c|c|c|c|c|c|c|c|c|}
\hline $\begin{array}{c}\text { Type of Energy } \\
\text { (Installed MWs) }\end{array}$ & $\begin{array}{c}\text { Wind } \\
\text { Energy } \\
\text { (MW) }\end{array}$ & $\begin{array}{c}\text { Solar } \\
\text { fotovoltaic } \\
\text { (MW) }\end{array}$ & $\begin{array}{c}\text { MiniHydrolic } \\
\text { energy } \\
(\mathbf{M W})\end{array}$ & $\begin{array}{c}\text { Biomass } \\
\text { (MW) }\end{array}$ & $\begin{array}{c}\text { Urban } \\
\text { waste } \\
\text { (MW) }\end{array}$ & $\begin{array}{c}\text { Absolute } \\
\text { Values }\end{array}$ & $\begin{array}{c}\text { Values per } \\
\text { surface } \\
\text { (kW/m } \mathbf{2})\end{array}$ & $\begin{array}{c}\text { Values per } \\
\text { population } \\
\text { (kW/inhabitan) }\end{array}$ \\
\hline Andalucía & 127.8 & 3.1 & 187.5 & 56.2 & 0 & 374.6 & 4.27 & 0.051 \\
\hline Castilla-León & 122.2 & 0.65 & 232.2 & 9 & 0 & 364 & 3.86 & 0.14 \\
\hline Cataluña & 59.8 & 0.61 & 213 & 5.7 & 39.72 & 318.83 & 10 & 0.051 \\
\hline La Rioja & 24.5 & 0.2 & 42.6 & 1 & 0 & 68.3 & 13.53 & 0.25 \\
\hline Madrid & 0.04 & 0.337 & 45.3 & 14.6 & 29 & 89.27 & 11.11 & 0.017 \\
\hline Murcia & 6 & 0.071 & 17 & 1 & 0 & 24 & 6.12 & 0.021 \\
\hline Navarra & 318.1 & 0.158 & 146.1 & 8.7 & 0 & 473 & 45.52 & 0.89 \\
\hline País Vasco & 0.03 & 0.1 & 47.56 & 22.43 & 0 & 70.12 & 9.69 & 0.033 \\
\hline Valencia & 2.8 & 0.538 & 39.6 & 3.2 & 0 & 46.13 & 1.98 & 0.011 \\
\hline TOTAL Y & Total: & Total: & Total: & Total: & Total: & Total: & Media: & Media: \\
MEDIAS & 661.2 & 5.7 & 970.86 & 121.83 & 68.72 & 1828.25 & 6.65 & 0.063 \\
\hline
\end{tabular}

Table II: Environmental impact analysis of different types of electricity production. (All data is in Tons by produced GWh)

\begin{tabular}{|c|c|c|c|c|c|c|c|c|}
\hline Energy Source & $\mathbf{C O}_{\mathbf{2}}$ & $\mathbf{N O}_{\mathbf{2}}$ & $\mathbf{S O}_{\mathbf{2}}$ & $\mathbf{C O}$ & Particles & $\begin{array}{c}\text { Nuclear } \\
\text { waste }\end{array}$ & Hydrocarbons & TOTAL \\
\hline Natural Gas ( combined cicle) & 824 & 0.251 & 0.336 & Trazas & 1.176 & - & TR & $\mathbf{8 2 5 . 8}$ \\
\hline Carbon & 1058.2 & 2986 & 2.971 & 0.267 & 1.626 & - & 0.102 & $\mathbf{1 0 6 6 . 1}$ \\
\hline Nuclear & 8.6 & 0.034 & 0.029 & 0.018 & 0.003 & 3.641 & 0.001 & $\mathbf{1 2 . 3}$ \\
\hline Solar thermal & 3.6 & sth & sth & sth & sth & - & sth & $\mathbf{3 . 6}$ \\
\hline Solar Fotovoltaic & 5.9 & 0.008 & 0.023 & 0.003 & 0.017 & - & 0.002 & $\mathbf{5 . 9}$ \\
\hline Eolian & 7.4 & sth & sth & sth & sth & - & sth & $\mathbf{7 . 4}$ \\
\hline Hydrolic & 6.6 & sth & sht & sth & sth & - & sth & $\mathbf{6 . 6}$ \\
\hline Biomass & 0 & 0.614 & 0.154 & 11.361 & 0.512 & - & 0.768 & $\mathbf{1 3 . 4}$ \\
\hline
\end{tabular}

